\title{
Two Dimensional Speckle Tracking Echocardiography Assessment of Left Ventricular Remodeling in Patients after Myocardial Infarction
}

\author{
Moustafa Kamal Eldin Ibrahim Khalil Saad", Khalid A El-khashab and Tamer M Ragab
}

Cardiology Department, Fayoum University, Egypt

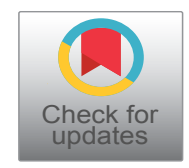

*Corresponding author: Dr. Moustafa Kamal Eldin Ibrahim Khalil Saad, Faculty of Medicine, Cardiology Department, Fayoum University, Gamma St, Keman Square, Fayoum, Egypt, Tel: 002-010-1140-4855

\begin{abstract}
Background: Adverse left ventricular remodelling (LVR), defined as progressive ventricular dilatation, distortion of chamber shape, myocardial hypertrophy and deteriorating function, begins in some patients who suffered from acute myocardial infarction (AMI), sometimes even after successful percutaneous coronary intervention $(\mathrm{PCl})$. If uninterrupted, it could lead to congestive heart failure (CHF) and a poor clinical outcome.
\end{abstract}

Aims: This study aims at evaluating the value of speckle tracking echocardiography in predicting LVR after successful $\mathrm{PCl}$ in AMI patients.

Materials and methods: Eighty-four AMI patients had a complete echocardiographic study, including speckle tracking, performed two days after $\mathrm{PCl}$ and then two months afterwards. The patients were then divided into two groups based on the presence of remodelling; $\mathrm{R}+$ (remodelling) group and R- (non-remodelling) group.

Results: At the baseline study, group $\mathrm{R}+$ showed significantly lower strain parameters than group R-. These included global longitudinal strain (GLS) (-11.14 $\pm 0.5 \mathrm{VS}$. -16.78 $\pm 0.4, p<0.0001)$, longitudinal strain rate $(-1.01 \pm 0.05 \mathrm{VS}$. $-1.07 \pm 0.04, p<0.0001)$, culprit longitudinal strain (CulLS) (-9.74 \pm 0.59 VS. $-15.68 \pm 0.49, P<0.0001)$, and culprit longitudinal strain rate $(-0.95 \pm 0.05$ VS. $-1.02 \pm 0.04, P<$ $0.0001)$. In the follow up study, all of the strain parameters studied were again significantly lower in the $\mathrm{R}+$ than the $\mathrm{R}$ group. The most sensitive and specific parameters were the GLS and CulLS (sensitivities of $91.7 \%$ and $95.8 \%$, respectively and specificities of $95 \%$ and $96.7 \%$, respectively).

Conclusion: Our findings show that impaired indices of LV deformation detected two days after successful PCI for AMI may provide a predictive value in early detection of LV remodelling.

\section{Keywords}

Left ventricular remodelling, Acute myocardial infarction, Speckle tracking echocardiography

\section{Introduction}

Improvement in the early diagnosis, invasive and medical treatment of acute myocardial infarction (AMI) lead to a reduction in the mortality rates associated with early and late complications of AMI. However, even complete revascularization does not exclude the risk of adverse left ventricular remodeling (LVR) [1].

Left ventricular remodeling is characterized by progressive enlargement and change in the shape of the LV cavity leading to systolic dysfunction. It occurs, as an adaptation to the tissue infarction, as a result of macro and microscopic changes at the cardiomyocyte, leading to structural and functional changes. Left ventricular remodeling is associated with worse outcomes and predisposes to heart failure [2].

Although various studies evaluated multiple clinical factors and routine echocardiographic parameters to try to detect LVR as a consequence of myocardial infarction, there are still gaps in our data, and some of the clinical factors or diagnostic parameters failed to identify patients prone to LVR [3].

Speckle tracking echocardiography (STE) is an echocardiographic method for evaluating and measuring global and regional strain (longitudinal, circumferential, radial and transverse), the precise indices of ventricular function. The main advantages of STE over strain

Citation: Saad MKEIK, El-khashab KA, Ragab TM (2020) Two Dimensional Speckle Tracking Echocardiography Assessment of Left Ventricular Remodeling in Patients after Myocardial Infarction. Int Arch Cardiovasc Dis 4:028. doi.org/10.23937/2643-3966/1710028

Accepted: April 09, 2020; Published: April 11, 2020

Copyright: (c) 2020 Saad MKEIK, et al. This is an open-access article distributed under the terms of the Creative Commons Attribution License, which permits unrestricted use, distribution, and reproduction in any medium, provided the original author and source are credited. 
assessment based on Doppler tissue imaging are that measurements are angle independent, and that it can distinguish active from passive movement of wall segments. Strain-based parameters have been validated in experimental and human studies as sensitive indicators of regional and global cardiac function [4].

Our aim was thus to evaluate the value of STE in the prediction of LVR in AMI patients after primary percutaneous coronary intervention $(\mathrm{PCl})$.

\section{Methods}

This study was a prospective cohort study conducted in Fayoum University Hospital, including patients from the emergency department and the in-patient cardiology department, after approval of the research and ethical committee.

Eighty-four patients diagnosed with acute myocardial infarction (AMI) were included. Inclusion criteria included typical chest pain, elevated cardiac biomarkers (troponin and CK-MB) and ST segment elevation on the electrocardiogram (ECG). All patients underwent $\mathrm{PCl}$ with stent implantation according to the ACC/AHA guidelines for STEMI. Prediction factors included number of diseased vessels and time to reperfusion. All patients then had a complete echocardiographic study [including 2D echo, a conventional Doppler study, tissue Doppler imaging (TDi), and speckle tracking echocardiography (STE)], performed two days after $\mathrm{PCl}$. The following parameters were measured: End-diastolic volume (EDV), end-systolic volume (ESV), ejection fraction (EF) and wall motion score index (WMSI) (by conventional 2D echo); $E$ \& $A$ waves, $E ; A$ ratio \& deceleration time (DT) (by Doppler); s', e' \& a' waves (by TDI); global longitudinal strain (GLS), longitudinal strain rate (LSr), global circumferential strain (GCS), circumferential strain rate (CSr), culprit longitudinal strain (CulLS) and culprit longitudinal strain rate (CulLSr) (by STE). The patients were then followed up after two months, where a new echocardiographic study was performed and all the above parameters were remeasured. The occurrence of left ventricular remodeling (LVR) was looked for specifically. LVR was defined as $\geq 20 \%$ increase in the end diastolic or end systolic volumes of the LV on follow up echocardiography in comparison to the baseline echocardiography. The patients were then divided into two groups according to the occurrence of remodeling; Remodeling $(\mathrm{R}+)$ group and Non-remodeling ( $\mathrm{R}-$ ) group.

Exclusion criteria included history of prior myocardial infarction, heart muscle disease (cardiomyopathy) with regional or global hypokinesia, valvular heart disease, significant arrhythmias (including atrial fibrillation), previous pacemaker or cardioverter defibrillator implantation, previous coronary artery by-pass grafting (CABG) or $\mathrm{PCl}$, and very poor image quality.

All patients received best guideline directed medical therapy as per the ACC/AHA guidelines for STMEI, including aspirin 75-100 mg once daily, ticagrelor $90 \mathrm{mg}$ bid, a high dose statin, a beta blocker (dosed according to heart rate and $\mathrm{BP}$ ), and a renin-angiotensin-aldosterone system (RAAS) inhibitor (dosed according to BP).

\section{Data entry and statistical analysis}

Data was collected, coded and analyzed using SPSS (Statistical Package for Social sciences) software (Version 25) on Windows 7, and a simple descriptive analysis in the form of percentage distribution, means and S.D. (Standard Deviation) was executed. Categorical data was analyzed by computing percentages, and consequent differences were tested statistically by applying Chi square tests for comparisons between groups; students' T-test to compare between two groups, a p-value of $<0.05$ was considered statistically significant.

\section{Results}

This study was conducted on eighty-four patients from the emergency and in-patient departments of Fayoum University Hospital in the duration from May 2017 till September 2018.

Basic characteristics in both groups ( $\mathbf{R}+, \mathbf{R}-)$, were as follows: the mean age of $\mathrm{R}+$ group was $58.9 \pm 9.3$ and that of the R-group was $58.3 \pm 6.9$. In the $\mathrm{R}+$ group $70.8 \%$ were males and $29.2 \%$ were females, while in the R- group $68.3 \%$ were males and $31.7 \%$ were females. Regarding different risk factors, in the $\mathrm{R}+$ group, $62 \%$ were smokers, $54 \%$ were diabetic and $58 \%$ were hypertensive, while in the R- group, $56 \%$ were smokers, $48 \%$ were diabetic and $56 \%$ were hypertensive (Table 1).

Regarding the angiographic results in both groups, the only statistically significant difference was in the time to reperfusion which was longer in the $\mathrm{R}+$ than the $\mathrm{R}$ - group, with a mean of $18.75 \pm 8.8$ hours and $5.55 \pm$ 2.45 hours, respectively, and a $p$ value of $<0.0001$. On the other hand, there were no statistically significant differences between both groups regarding the number of diseased vessels or the infarct related artery (IRA); in the $R+$ group $50 \%$ had the LAD, 16\% had the LCX and $33 \%$ had the RCA as the IRA, while in the R- group $48 \%$ had the LAD, $21 \%$ had the LCX and $30 \%$ had the RCA as the IRA (Table 2).

The basic echocardiographic results in the baseline echocardiography study showed that only the wall motion score index (WMSI) was statistically significant, where its value was higher in the $\mathrm{R}+$ than the $\mathrm{R}$ - group, with a mean of $1.58 \pm 0.08$ and $1.23 \pm 0.07$ respectively, and a $p$ value of $<0.0001$. The EF, EDV and ESV were less in the $\mathrm{R}+$ than in the R-group, but there was no statistically significant difference.

The follow up echocardiography study showed that there was a statistically significant difference between both groups regarding the EF, EDV and ESV; the EF was 
Table 1: Basic characteristics and risk factors in both groups.

\begin{tabular}{|c|c|c|c|c|c|}
\hline \multirow[t]{2}{*}{ Variables } & \multicolumn{2}{|c|}{$\begin{array}{l}\text { Patients with Remodeling } \\
(\mathrm{R}+)(\mathrm{N}=\mathbf{2 4})\end{array}$} & \multicolumn{2}{|c|}{$\begin{array}{l}\text { Patients without Remodeling } \\
(\mathrm{R}-)(\mathrm{N}=60)\end{array}$} & \multirow[t]{2}{*}{ P-value } \\
\hline & Mean & \pm SD & Mean & $\pm \mathrm{SD}$ & \\
\hline Age & 58.92 & 9.38 & 58.32 & 6.99 & 0.749 \\
\hline Variables & $\mathbf{N}$ & $\%$ & $\mathbf{N}$ & $\%$ & P-value \\
\hline \multicolumn{6}{|l|}{ Sex } \\
\hline Male & 17 & 70.8 & 41 & 68.3 & \multirow[t]{2}{*}{0.823} \\
\hline Female & 7 & 29.2 & 19 & 31.7 & \\
\hline \multicolumn{6}{|l|}{ Smoking } \\
\hline Yes & 15 & 62.5 & 34 & 56.7 & \multirow[t]{2}{*}{0.624} \\
\hline No & 9 & 37.5 & 26 & 43.3 & \\
\hline \multicolumn{6}{|c|}{ Hypertension } \\
\hline Yes & 14 & 58.3 & 34 & 56.7 & \multirow[t]{2}{*}{0.889} \\
\hline No & 10 & 41.7 & 26 & 43.3 & \\
\hline \multicolumn{6}{|l|}{ Diabetes } \\
\hline Yes & 13 & 54.2 & 29 & 48.3 & \multirow[t]{2}{*}{0.629} \\
\hline No & 11 & 45.8 & 31 & 51.7 & \\
\hline
\end{tabular}

\#Independent t-test; \#Chi-square $\left(\chi^{2}\right)$ test.

Table 2: Angiographic results in both groups.

\begin{tabular}{|c|c|c|c|c|c|}
\hline \multirow[t]{2}{*}{ Variables } & \multicolumn{2}{|c|}{$\begin{array}{l}\text { Patients with Remodeling (R+) } \\
(\mathrm{N}=24)\end{array}$} & \multicolumn{2}{|c|}{$\begin{array}{l}\text { Patients without Remodeling (R-) } \\
(\mathrm{N}=60)\end{array}$} & \multirow[t]{2}{*}{ P-value } \\
\hline & Mean & \pm SD & Mean & \pm SD & \\
\hline Number of diseased vessels & 1.83 & 0.82 & 1.77 & 0.76 & 0.725 \\
\hline Time to reperfusion & 18.75 & 8.89 & 5.55 & 2.45 & $<0.0001$ \\
\hline Variables & $\mathbf{N}$ & $\%$ & $\mathbf{N}$ & $\%$ & P-value \#\# \\
\hline \multicolumn{6}{|l|}{ IRA } \\
\hline LAD & 12 & 50.0 & 29 & 48.3 & \multirow[t]{3}{*}{0.868} \\
\hline LCX & 4 & 16.7 & 13 & 21.7 & \\
\hline $\mathrm{RCA}$ & 8 & 33.3 & 18 & 30.0 & \\
\hline
\end{tabular}

\#Independent t-test; \#"Chi-squared $\left(\chi^{2}\right)$ test.

IRA: infarct related artery; LAD: left anterior descending artery; LCX: left circumflex artery; RCA: right coronary artery.

Table 3: Basic echocardiographic results in both groups.

\begin{tabular}{|c|c|c|c|c|c|}
\hline \multirow[t]{2}{*}{ Variables } & \multicolumn{2}{|c|}{$\begin{array}{l}\text { Patients with Remodeling (R+) } \\
(\mathrm{N}=\mathbf{2 4})\end{array}$} & \multicolumn{2}{|c|}{$\begin{array}{l}\text { Patients without Remodeling (R-) } \\
(\mathrm{N}=60)\end{array}$} & \multirow[t]{2}{*}{ P-value } \\
\hline & Mean & \pm SD & Mean & \pm SD & \\
\hline \multicolumn{6}{|c|}{ Two days after $\mathrm{PCI}$} \\
\hline EF & 50.63 & 2.03 & 51.29 & 3.96 & 0.322 \\
\hline EDV & 87.25 & 9.04 & 89.55 & 8.15 & 0.261 \\
\hline ESV & 43.08 & 4.91 & 43.70 & 5.94 & 0.654 \\
\hline WMSI & 1.58 & 0.08 & 1.23 & 0.07 & $<0.0001$ \\
\hline \multicolumn{6}{|c|}{ After 2 months } \\
\hline EF & 50.67 & 2.27 & 54.81 & 4.17 & $<0.0001$ \\
\hline EDV & 106.36 & 11.32 & 87.59 & 8.23 & $<0.0001$ \\
\hline ESV & 52.46 & 6.08 & 39.69 & 5.98 & $<0.0001$ \\
\hline
\end{tabular}

\#Independent t-test.

EF: ejection fraction; EDV: end diastolic volume, ESV: end systolic volume, WMSI: wall motion score index. 
less in the $\mathrm{R}+$ than the $\mathrm{R}$ - group (mean values of 50.6 \pm 2.27 and $54.8 \pm 4.1$ respectively, with a $p$ value of $<$ $0.0001)$, the EDV was higher in the $\mathrm{R}+$ than the $\mathrm{R}$ - group (mean values of $106.3 \pm 11.3$ and $87.5 \pm 8.2$ respectively, with a $p$ value of $<0.0001$ ), and the ESV was higher in the $\mathrm{R}+$ than the $\mathrm{R}$ - group (mean values of $52.4 \pm 6$ and $39.6 \pm 5.9$ respectively, with a $p$ value of $<0.0001$ ) (Table 3).

The Doppler study done at the baseline echocardiography, showed many statistically significant differences between both groups regarding the $A, E / A$ and Deceleration Time (DT) values, where the $A$ wave was lower in the $\mathrm{R}+$ than the $\mathrm{R}$ - group $(67.5 \pm 2.5$ and 74.2 \pm 2.5 respectively, with a $p$ value of $<0.0001$ ), the $E / A$ ratio was higher in the $\mathrm{R}+$ than the $\mathrm{R}$ - group $(1.2 \pm 0.03$ and $1.08 \pm 0.08$ respectively, with a $p$ value of $<0.0001)$, and the DT was less in the R+ than the R-group ( 151.8 \pm 8.8 and $183.1 \pm 6.8$ respectively, with a $p$ value of $<$ $0.0001)$. There was no statistically significant difference in the $E$ wave value between both subgroups.

In regards to the tissue Doppler imaging (TDI) study, the $\mathrm{e}^{\prime}$ was significantly lower in the $\mathrm{R}+$ than the $R$ - group (5.2 \pm 0.3 and $6.2 \pm 0.6$ respectively, with a $p$ value of $<0.0001$ ), and the $\mathrm{E} / \mathrm{e}^{\prime}$ ratio was significantly higher in the $\mathrm{R}+$ than $\mathrm{R}-$ group $(15.5 \pm 1$ and $13.02 \pm$ 1.4 respectively, with a $p$ value of $<0.0001$ ). The $a^{\prime}$ and $s^{\prime}$ values did not show significant differences between both groups (Table 4).

The speckle tracking echocardiography data derived from the baseline study, showed statistically significant difference in the following values:

- The global longitudinal strain (GLS) was lower in the $\mathrm{R}+$ than the $\mathrm{R}$ - group (mean values of $-11.14 \pm$ 0.59 and $-16.78 \pm 0.49$ respectively, with a $p$ value of $<0.0001$ ).

- The longitudinal strain rate ( $\mathrm{LSr}$ ) was lower in the $\mathrm{R}+$ than the $\mathrm{R}$ - group (mean values of $-1.01 \pm 0.05$ and $1.07 \pm 0.04$ respectively, with a $p$ value of $<$
0.0001).

- The culprit longitudinal strain (CulLS) was lower in the $\mathrm{R}+$ than the $\mathrm{R}$ - group (mean values of $-9.74 \pm$ 0.59 and $-15.68 \pm 0.49$ respectively, with a $p$ value of $<0.0001$ ).

- The culprit longitudinal strain rate (CulLSr) was lower in the $\mathrm{R}+$ than the $\mathrm{R}$ - group (mean values of $-0.95 \pm 0.05$ and $-1.02 \pm 0.04$ respectively, with a $p$ value of $<0.0001$ ).

- However, the global circumferential strain (GCS) and the circumferential strain rate (CSr) did not show a statistically significant difference between both groups.

In the follow up LV deformation study done after $\mathbf{2}$ months, all the parameters showed a statistically significant difference, where:

- The global longitudinal strain (GLS) was lower in the $\mathrm{R}$ + than the $\mathrm{R}$ - group (mean values of $-11.48 \pm$ 0.59 and $-17.9 \pm 0.51$ respectively, with a $p$ value of $<0.0001$ ).

- The longitudinal strain rate (LSr) was lower in the $\mathrm{R}+$ than the $\mathrm{R}$ - group (mean values of $-0.99 \pm 0.05$ and $-1.14 \pm 0.04$ respectively, with a $p$ value of $<$ 0.0001).

- The global circumferential strain (GCS) was lower in the $\mathrm{R}+$ than the $\mathrm{R}$ - group (mean values of $-17.03 \pm 0.39$ and $-17.32 \pm 0.57$ respectively, with a $p$ value of $<0.023$ ).

- The circumferential strain rate (CSr) was lower in the $\mathrm{R}+$ than the $\mathrm{R}$ - group (mean values of $-1.26 \pm$ 0.05 and $-1.29 \pm 0.06$ respectively, with a $p$ value of $<0.01$ ).

- The culprit longitudinal strain (CulLS) was lower in the $\mathrm{R}+$ than the $\mathrm{R}$ - group (mean values of $-10.14 \pm$ 0.59 and $-16.63 \pm 0.49$ respectively, with a $p$ value of $<0.0001$ ).

Table 4: Doppler results two days after $\mathrm{PCl}$ in both groups.

\begin{tabular}{|c|c|c|c|c|c|}
\hline \multirow[t]{2}{*}{ Variables } & \multicolumn{2}{|c|}{$\begin{array}{l}\text { Patients with Remodeling (R+) } \\
(\mathrm{N}=\mathbf{2 4})\end{array}$} & \multicolumn{2}{|c|}{$\begin{array}{l}\text { Patients without Remodeling (R-) } \\
(\mathrm{N}=60)\end{array}$} & \multirow[t]{2}{*}{ P-value } \\
\hline & Mean & \pm SD & Mean & \pm SD & \\
\hline$E$ & 81.04 & 3.06 & 80.18 & 4.94 & 0.431 \\
\hline$A$ & 67.54 & 2.57 & 74.27 & 2.52 & $<0.0001$ \\
\hline$E / A$ & 1.20 & 0.03 & 1.08 & 0.08 & $<0.0001$ \\
\hline DT & 151.83 & 8.82 & 183.17 & 6.83 & $<0.0001$ \\
\hline Tissue Doppler & Mean & \pm SD & Mean & \pm SD & P-value ${ }^{\#}$ \\
\hline$e^{\prime}$ & 5.24 & 0.33 & 6.22 & 0.64 & $<0.0001$ \\
\hline Ele' & 15.52 & 1.01 & 13.02 & 1.49 & $<0.0001$ \\
\hline$a^{\prime}$ & 8.59 & 0.38 & 8.65 & 0.40 & 0.554 \\
\hline$s^{\prime}$ & 6.69 & 0.35 & 6.84 & 0.41 & 0.138 \\
\hline
\end{tabular}

\#Independent t-test; DT: deceleration time. 
Table 5: Speckle tracking echocardiography (STE) results in both groups.

\begin{tabular}{|c|c|c|c|c|c|}
\hline \multirow[t]{2}{*}{ Variables } & \multicolumn{2}{|c|}{$\begin{array}{l}\text { Patients with Remodeling } \\
(\mathrm{N}=24)\end{array}$} & \multicolumn{2}{|c|}{$\begin{array}{l}\text { Patients without remodeling } \\
(\mathrm{N}=60)\end{array}$} & \multirow[t]{2}{*}{ P-value } \\
\hline & Mean & \pm SD & Mean & \pm SD & \\
\hline \multicolumn{6}{|c|}{ Two days after PCI } \\
\hline GLS & -11.14 & 0.59 & -16.78 & 0.49 & $<0.0001$ \\
\hline LSr & -1.01 & 0.05 & -1.07 & 0.04 & $<0.0001$ \\
\hline GCS & -16.62 & 0.38 & -16.71 & 0.57 & 0.492 \\
\hline $\mathrm{CSr}$ & -1.23 & 0.05 & -1.24 & 0.06 & 0.06 \\
\hline CulLS & -9.74 & 0.59 & -15.68 & 0.49 & $<0.0001$ \\
\hline CulLSr & -0.95 & 0.05 & -1.02 & 0.04 & $<0.0001$ \\
\hline \multicolumn{6}{|c|}{ After 2 months } \\
\hline GLS & -11.48 & 0.59 & -17.90 & 0.51 & $<0.0001$ \\
\hline LSr & -0.99 & 0.05 & -1.14 & 0.04 & $<0.0001$ \\
\hline GCS & -17.03 & 0.39 & -17.32 & 0.57 & 0.023 \\
\hline $\mathrm{CSr}$ & -1.26 & 0.05 & -1.29 & 0.06 & 0.010 \\
\hline CulLS & -10.14 & 0.59 & -16.63 & 0.49 & $<0.0001$ \\
\hline CulLSr & -0.96 & 0.08 & -1.10 & 0.04 & $<0.0001$ \\
\hline
\end{tabular}

\#Independent t-test.

GLS: global longitudinal strain; LSr: longitudinal strain rate; GCS: global circumferential strain; CSr: circumferential strain rate; CulLS: culprit longitudinal strain; CulLSr: culprit longitudinal strain rate.

Table 6: Echocardiographic parameters at baseline study predicting LV remodeling in the 2-months follow-up.

\begin{tabular}{|c|c|c|c|c|}
\hline & AUC & Cut off point & Sensitivity \% & Sensitivity \% \\
\hline \multicolumn{5}{|c|}{ Doppler 2 days after PCI } \\
\hline A & 0.832 & 70.5 & 79.2 & 80 \\
\hline E/A & 0.815 & 1.15 & 79.2 & 86.3 \\
\hline$e^{\prime}$ & 0.883 & 5.55 & 75 & 81.3 \\
\hline$E / e^{\prime}$ & 0.813 & 13.69 & 83.3 & 68.3 \\
\hline DT & 0.930 & 172.5 & 87.5 & 90 \\
\hline \multicolumn{5}{|c|}{ Strain Echo 2 days after $\mathrm{PCl}$} \\
\hline GLS & 0.890 & -14.0 & 91.7 & 95 \\
\hline LSr & 0.825 & -1.06 & 83.3 & 65.0 \\
\hline CulLS & 0.951 & -12.0 & 95.8 & 96.7 \\
\hline CulLSr & 0.873 & -0.99 & 83.3 & 73.3 \\
\hline WMSI & 0.957 & 1.4 & 87.5 & 93.3 \\
\hline
\end{tabular}

DT: deceleration time; GLS: global longitudinal strain; LSr: longitudinal strain rate; CulLS: culprit longitudinal strain; CulLSr: culprit longitudinal strain rate; WMSI: wall motion score index.

- The culprit longitudinal strain rate (CulLSr) was lower in the $\mathrm{R}+$ than the $\mathrm{R}$ - group (mean values of $-0.96 \pm 0.08$ and $-1.1 \pm 0.04$ respectively, with a $p$ value of $<0.0001$ ) (Table 5).

The receiver operating characteristics (ROC) curves of variables, which were significantly different, from the baseline study, showed a significant difference between the $\mathrm{R}+$ and $\mathrm{R}$ - groups. The most sensitive and specific parameters were the culprit longitudinal strain (CulLS) and the global longitudinal strain (GLS), where both showed sensitivities of $95.8 \%$ and $91.7 \%$ respectively, and specificities of $96.7 \%$ and $95 \%$ respectively.
Out of the non-strain derived parameters, the wall motion score index (WMSI) and the deceleration time (DT) showed the highest specificity, where the specificities were $90 \%$ and $93.3 \%$ respectively (Table 6 ).

\section{Discussion}

\section{Time to reperfusion}

Our study shows that there was a significant longer mean time from first symptoms occurrence to reperfusion in the group of AMI patients who suffered from adverse LVR, where the mean duration was 18.75 hours \pm 8.89 versus 5.55 hours \pm 2.45 in the non-remodeling 
subgroup, with a $p$ value of $<0.0001$. This result is comparable to the results of a study done by Hsiao, et al. [5] in which the door to balloon time was longer in the remodeling group. Also this same finding was detected by Liszka, et al. [6], but other studies done by Bolognese, et al. [7] and cerisano, et al. [8], did not detect such a finding.

The first symptoms-reperfusion time consists of three parts: a) Time to first medical contact, b) Time to medical center and c) Door to balloon time. The relatively long overall time to reperfusion found in our study was mainly due to patients' unnecessary emergency call delay despite clear symptoms or ambiguous and atypical general symptoms, which were not primarily recognized as serious cardiovascular symptoms (e.g. gastrointestinal-like symptoms in inferior wall ischemia). The LVR occurring despite successful reperfusion may be a consequence of a lower number of viable cardiomyocytes in the infarct area at the time of reperfusion, which is not sufficient to prevent adverse remodeling $[9,10]$.

\section{Wall motion score index}

Our study shows that there was a significantly higher wall motion score index (WMSI) value in the remodeling group than in the non-remodelers. This finding is comparable to the results of a study done by Lo-
boz-Grudzien, et al. [11], who found that a WMSI value of $\geq 1.5$ was predictive of progressive left ventricular dilatation (PLVD) after myocardial infarction.

In a study done by Eek, et al. [12] it was found that a WMSI value of more than 1.44 indicated an infarct size of more than $12 \%$ of the myocardium (infarct size was calculated by infarct volume as a percentage of total myocardial volume, quantified by MRI). Final infarct size is a strong predictor of mortality and major adverse cardiovascular events. Current reperfusion therapy is effective, resulting in a relative reduction of infarct size achieved, typically $40 \%$ by thrombolysis and $60 \%$ by primary $\mathrm{PCl}$. The reduced mortality rate observed in the reperfusion era is largely attributable to a reduction of final infarct size. This WMSI value is comparable to the cutoff value in our study which is 1.4 , at which both the sensitivity and specificity for the prediction of LV adverse remodeling were $87.5 \%$ and $93.3 \%$, respectively (Figure 1).

\section{Doppler echocardiography}

In the study done by Cerisano, et al. [8] it was found that the assessment of LV filling pattern on Doppler echocardiography provides additional and important information in the setting of $\mathrm{AMI}$, allowing identification of patients at high risk for progressive LV dilation after AMI. A restrictive filling pattern, as expressed by a short

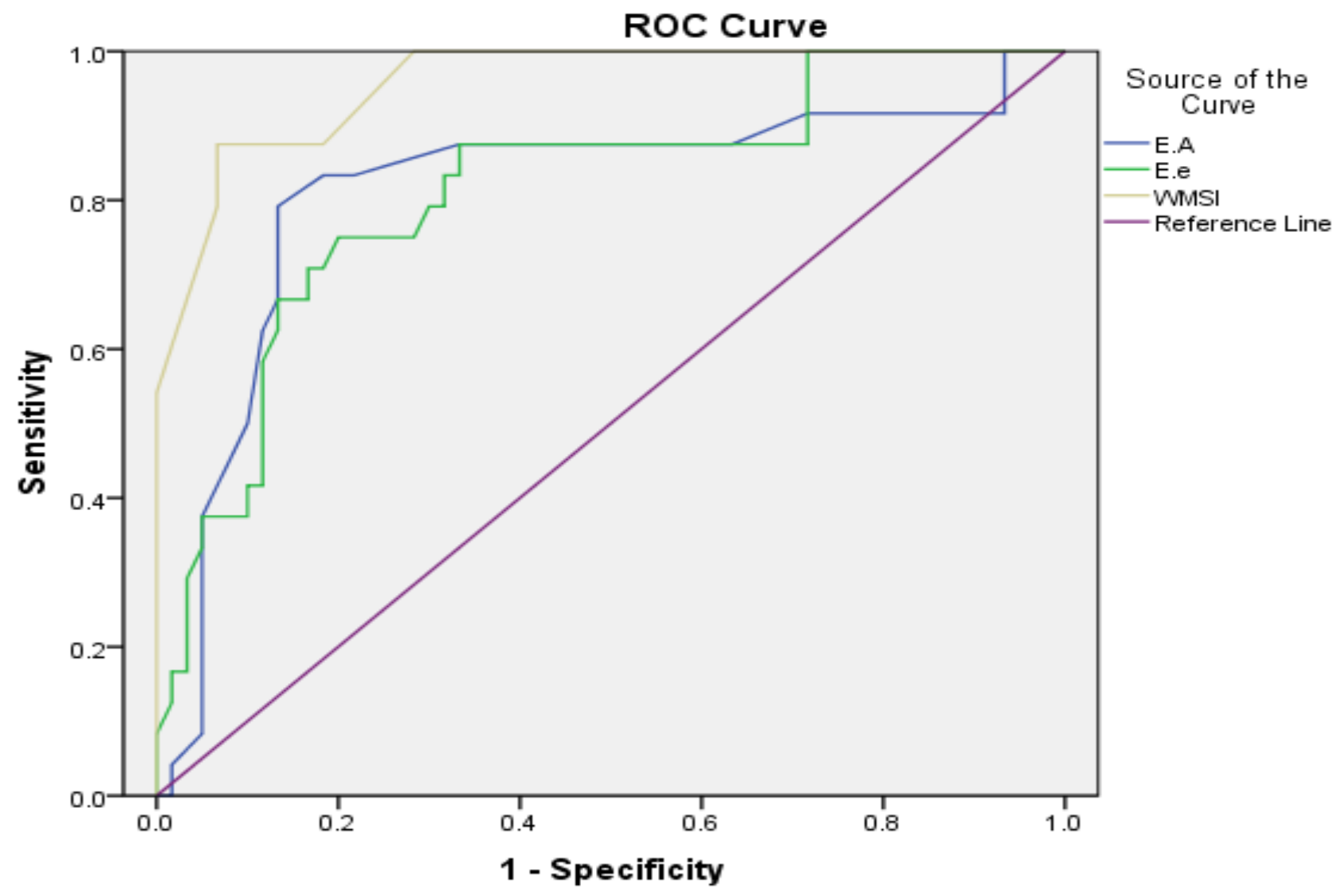

Diagonal segments are produced by ties.

Figures 1: ROC curve of the Doppler ratios and WMSI. 
DT, was the most powerful predictor of LV remodeling, and the degree of $\mathrm{LV}$ dilation was related to the severity of impairment of LV filling.

Previous studies have demonstrated that infarct size is one of the major factors that promote LV remodeling $[13,14]$. On the other hand, the size of the infarct zone has been shown to influence the diastolic filling pattern, with the large infarcts exhibiting a "restrictive" filling pattern. Therefore, a short DT, indicative of a restrictive filling pattern, might simply reflect an increasing infarct size and consequently a higher risk of LV dilation [15].

In agreement with the aforementioned observations, our study showed that the $\mathrm{R}+$ group (with remodeling) showed a significantly lower value of the A wave, shorter deceleration time and a higher E/A value. The tissue Doppler also showed a significantly lower e` and a higher $\mathrm{E} / \mathrm{e}$ ' values in the $\mathrm{R}+$ group.

Our results thus also suggest a restrictive filling pattern in the $\mathrm{R}+$ group, with the DT being the most specific Doppler parameter (at a cutoff value of $\mathbf{1 7 2 . 5} \mathbf{m s}$, sensitivity of $\mathbf{8 7 . 5 \%}$ and specificity of $\mathbf{9 0 \% )}$ for detection of LVR after 2 months.

Our study thus shows that early noninvasive as- sessment of trans-mitral flow velocity by Doppler echocardiography allows identification of patients at high risk for progressive LV dilation within 2 months after reperfused AMI. A restrictive filling pattern is a powerful predictor of LV remodeling, with the deceleration time being the most Doppler specific parameter (Figure 2).

\section{Speckle tracking echocardiography derived strain parameters}

There have been extensive studies about global longitudinal strain (GLS), global circumferential strain (GCS), and longitudinal and circumferential strain rates (LSr, CSr), proposing them as predictors for reworking. However, most of these studies had the limitation of small patient number. Some studies demonstrated that GLS may be a powerful prognosticator for reworking, others claimed GCS to be the best prognosticator, and other studies even claimed that circumferential strain rate was the simplest predictor of transforming.

Our study shows that, out of the various strain parameters measured 2 days after $\mathrm{PCl}$, the GLS, LSr, CuILS and therefore the CulLSr were significantly lower within the subgroup of patients that afterwards

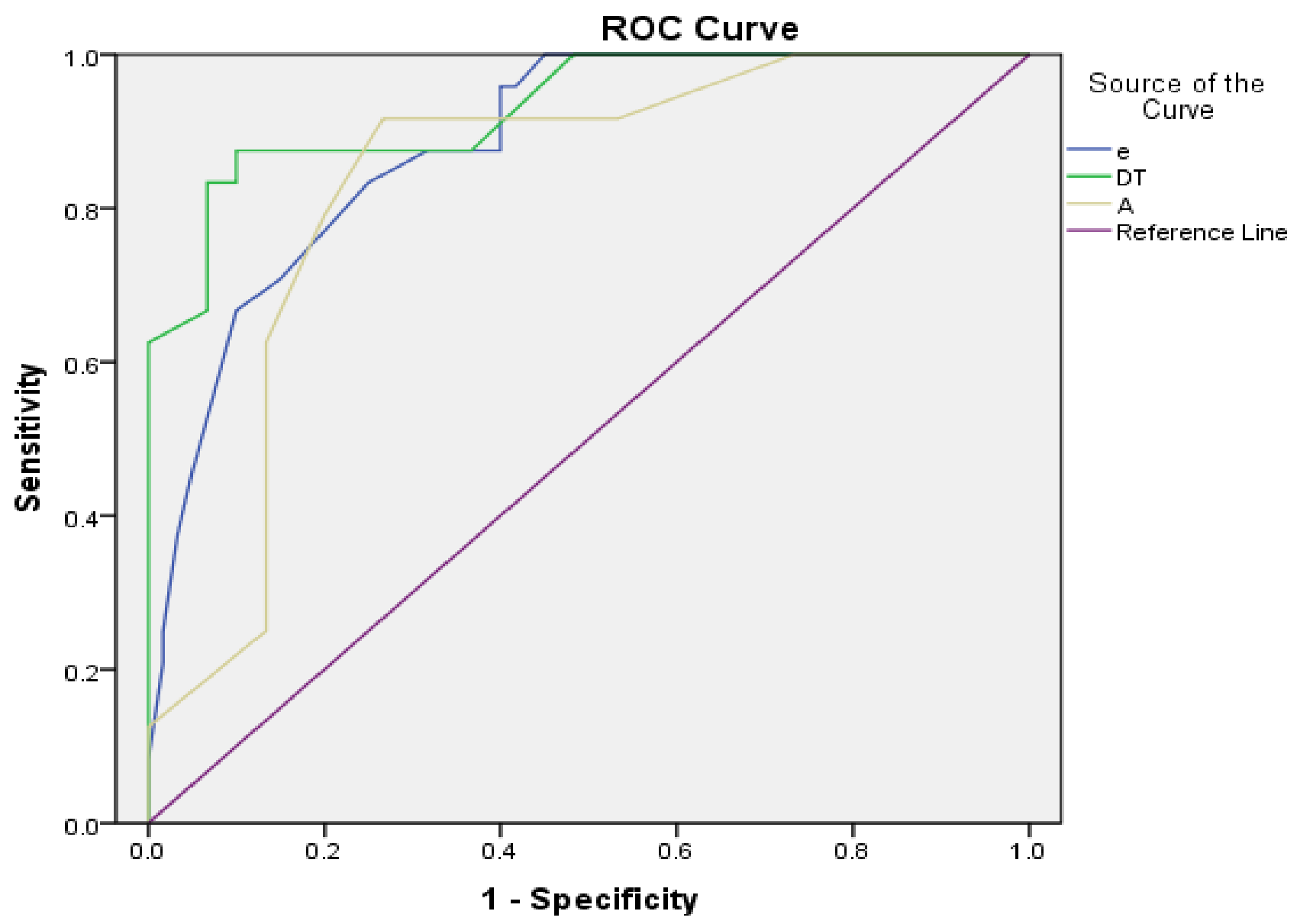

Diagonal segments are produced by ties.

Figure 2: ROC curve of the mitral inflow Doppler parameter. 
suffered from adverse LV remodeling. In 2008, Park, et al. demonstrated that GLS predicts remodeling, where remodeling was defined as $>15 \%$ increase in EDV. They targeted only anterior wall infarctions with a patient population of fifty. Lacalzada, et al. [16] also illustrated that GLS predicts remodeling in STEMI in a study including ninety-seven low risk patients. Only 20 out of 97 patients developed remodeling in their study. A large study by Joyce, et al. [17] reported an association between GLS and adverse LV dilatation after STEMI in 1,041 patients. The population was divided into 2 groups depending on their GLS (above or below -15\%). Patients with baseline GLS less than $-15.0 \%$ exhibited greater LV dilatation at 3-and 6-month follow-ups compared with patients with GLS equal to or above $-15.0 \%$. This is almost similar to our study that showed that at a cutoff value of $-14 \%$, the sensitivity and specificity of GLS to predict LV remodeling were $91.7 \%$ and $95 \%$ respectively. On the opposite hand, Bonios, et al. [18] stated that in their research on potential predictors of LV remodeling in patients with acute anterior wall myocardial infarction, apical CS was a stronger predictive marker of LV remodeling as compared to LS. One potential pathophysiological explanation of this finding is that LV CS plays a more pivotal role in maintaining LV structure, hence a worse circumferential CS might contribute to LV remodeling. In support of this hy- pothesis are the results of the study by Aikawa, et al. [19], where, in patients with an anterior infarction, apical regional wall stress was an independent predictor of subsequent LV remodeling after AMI. But it's worth mentioning that in both of these studies, only patients with anterior myocardial infarction were included.

The VALIANT Echo study, in contrary to our study, demonstrated that circumferential strain rate was predictive of LVR but GLS and LSr were not. That study investigated 603 patients with LV dysfunction or heart failure after myocardial infarction. Only 311 cases had adequate image quality to allow assessment of all longitudinal and circumferential strain and strain rate. The GLS and LSRs were derived only from the mean of apical 4- and 2-chamber views. Probably, the mean value of all complete 12 segments was not representative of worldwide values. It is worth mentioning that those patients were enrolled before the systematic use of primary $\mathrm{PCl}$ and other guideline-based anti-remodeling therapies [20].

In our study, we also investigated the culprit longitudinal strain and strain rate (CulLS, CulLSr) which were defined as the average longitudinal strain and strain rates of the territories of the culprit vessels, and both showed significant difference between the groups of remodelers and non-remodelers (both were significantly

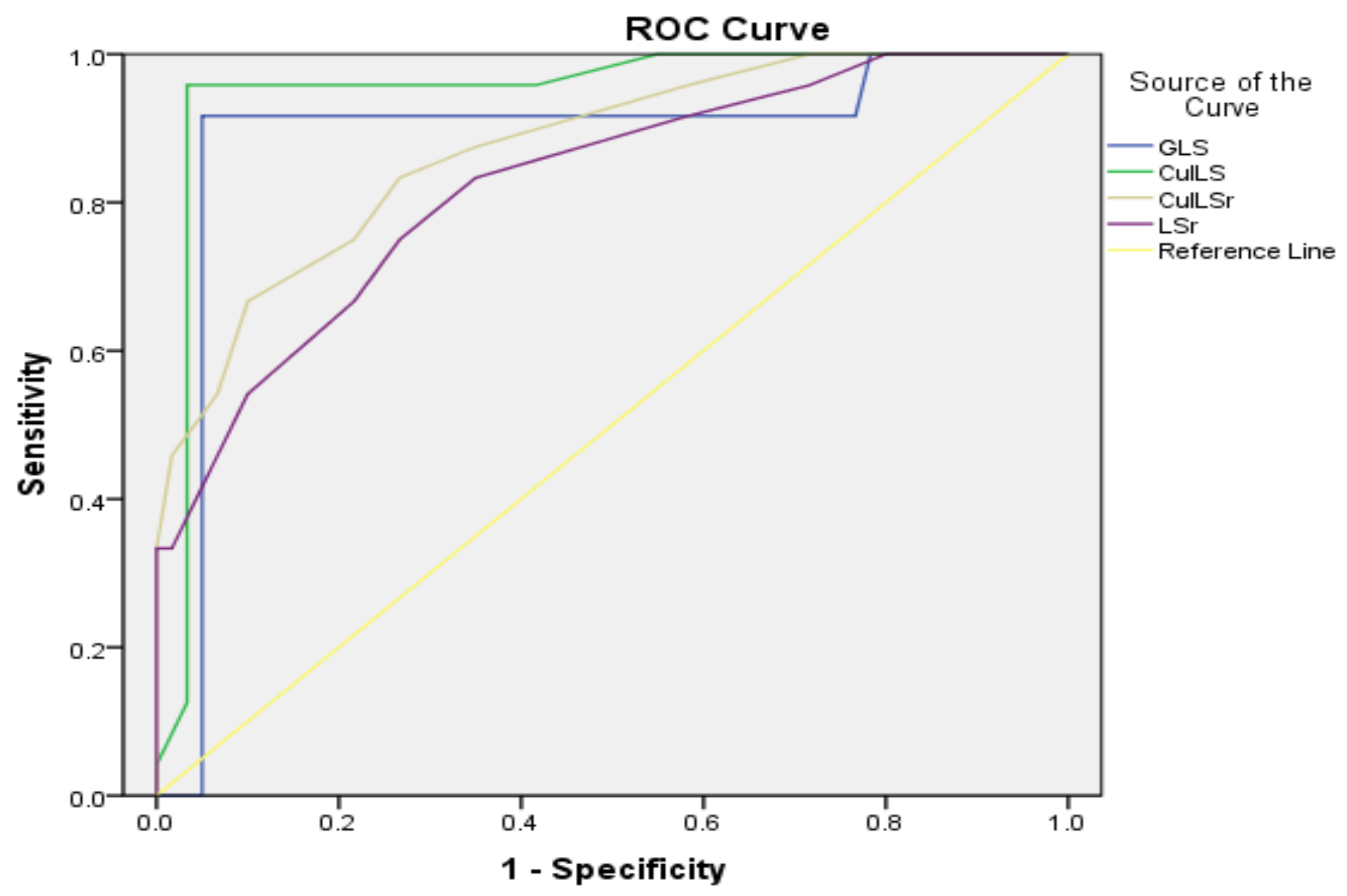

Diagonal segments are produced by ties.

Figure 3: ROC Curve of the LV strain study parameters. 
lower). These results are in partial concordance with the results of the study by Hsiao, et al. [5], which demonstrated that, out of both of these values, only the CulLSr showed a significant difference (was significantly lower within the adverse remodeling group) (Figure 3).

\section{What is the best parameter for prediction of ad- verse $L V$ remodeling?}

In our study, the CulLS and therefore the GLS (Iongitudinal strain parameters) were the most sensitive and specific parameters for the prediction of LVR with sensitives of $95.8 \%$ and $91.7 \%$, respectively and specificities of $96.7 \%$ and $95 \%$, respectively. Gjesdal, et al. [21], discovered that the GLS level identified by 2D speckle tracking echocardiography is closely correlated to myocardial infarct size as determined by contrast-enhanced resonance imaging during chronic ischemic heart condition. A strain value of $-15 \%$ has $83 \%$ sensitivity and $93 \%$ specificity at the worldwide level and $76 \%$ sensitivity and $95 \%$ specificity at the territorial level (territory of the culprit vessel) to spot infarction.

Longitudinal strain is more sensitive to early cardiac attack and circumferential strain may be preserved initially. This is often because subendocardium is more susceptible to ischemia. Because longitudinal fibers are in the subendocardial region and circumferential fibers are within the mid-wall region of the myocardium, thus the longitudinal fibers are more vulnerable to ischemia, resulting in cardiac long-axis systolic dysfunction which is reflected by impaired GLS. Consequently, it is reasonable that GLS is an early marker for cardiac dysfunction and GCS gets impaired in advanced patients with decompensated heart failure, which may explain why GCS was not found to be an early predictor of adverse LVR in our study. This hypothesis should be further verified [22].

\section{Limitations of the study}

1. Our cohort of patients was relatively small, and it was limited to patients with few complications. Patients who required mechanical ventilation were difficult to be included due to poor image quality.

2. Deformation imaging based on speckle tracking technique relies on above-average image quality for good data extraction, and continuous endocardial border motion would be the major determinant in enrollment.

\section{Conclusion}

Adverse LV remodeling occurred in $30 \%$ of $\mathrm{AMI}$ patients even after $\mathrm{PCl}$. The 2D speckle tracking echocardiography proved to be a promising, feasible, and noninvasive modality to evaluate myocardial deformation in this cohort. In our study, CulLS and GLS were the most sensitive and specific predictors of adverse LV remod- eling.

\section{Ethics}

This study was reviewed and approved by the Fayoum University-Faculty of Medicine (Research Ethical Committee). The official approval was obtained from the general director of hospital and the manager of the outpatient clinic and the head of the Cardiology department.

\section{Consent to Participate}

The study was performed after explaining its objectives and confidentiality was expressed to the participants. Written consent was taken from the participants as an agreement to join the study before clinical examination and laboratory investigation. All participants had the right to not participate in the study.

\section{Declaration}

The authors declare that this manuscript did not previously publish or considered for publication in any other journal. The authors do not hold any stocks or shares, fees, funding or salary from any organization that may in any way gain or lose financially from the publication of this manuscript, either now or in the future.

\section{Competing Interests}

There is no conflict of interest as there are no commercial or financial relationships from any institution or organization that could be construed as a potential conflict and all the expenses are covered by the authors.

\section{Consent to Publish}

Not applicable.

\section{Availability of Data and Materials}

All the data are available on an excel sheet and also SPSS format and if needed the corresponding author is welcome to send it upon request.

\section{References}

1. Funaro S, Galiuto L, Boccalini F, Cimino S, Canali E, et al. (2011) Determinants of microvascular damage recovery after acute myocardial infarction: Results from the Acute Myocardial Infarction Contrast Imaging (AMICI) multi-centre study. Eur J Echocardiogr 12: 306-312.

2. Arnold SV, Spertus JA, Masoudi FA, Daugherty SL, Maddox TM, et al. (2013) Beyond medication prescription as performance measures: Optimal secondary prevention medication dosing after acute myocardial infarction. J Am Coll Cardiol 62: 1791-1801.

3. Seropian IM, Sonnino C, Van Tassell BW, Biasucci LM, Abbate A (2015) Inflammatory markers in ST-elevation acute myocardial infarction. Eur Heart J Acute Cardiovasc Care 5: 382-395

4. Marwick TH, Leano RL, Brown J, Sun JP, Hoffmann R, et al. (2009) Myocardial strain measurement with 2-dimensional speckle-tracking echocardiography: Definition of normal range. JACC Cardiovasc Imaging 2: 80-84. 
5. Hsiao JF, Chung CM, Chu CM, Lin YS, Pan KL, et al. (2016) Two-dimensional speckle tracking echocardiography predict left ventricular remodeling after acute myocardial infarction in patients with preserved ejection fraction. PLoS One 11: e0168109.

6. Liszka J, Haberka M, Tabor Z, Finik M, Gąsior Z (2014) Two dimensional speckle tracking echocardiography assessment of left ventricular remodeling in patients after myocardial infarction and primary reperfusion. Arch Med Sci 6: 1091-1100.

7. Bolognese L, Neskovic A, Parodi G, Cerisano G, Buonamici $P$, et al. (2002) Left ventricular remodeling after primary coronary angioplasty: Patterns of left ventricular dilation and long-term prognostic implications. Circulation 106: 2351-2357.

8. Cerisano G, Bolognese L, Carrabba N, Buonamici P, Santoro GM, et al. (1999) Doppler-derived mitral deceleration time: An early strong predictor of left ventricular remodeling after reperfused anterior acute myocardial infarction. Circulation 99: 230-236.

9. Nicolosi GL, Golcea S, Ceconi C, Parrinello G, Decarli A, et al. (2009) Effects of perindopril on cardiac remodeling and prognostic value of pre-discharge quantitative echocardiographic parameters in elderly patients after acute myocardial infarction: The PREAMI echo sub-study. Eur Heart $\mathrm{J}$ 30: 1656-1665.

10. Bertini M, Mollema SA, Delgado V, Antoni ML, Ng AC, et al. (2009) Impact of time to reperfusion after acute myocardial infarction on myocardial damage assessed by left ventricular longitudinal strain. Am J Cardiol 104: 480-485.

11. Loboz-Grudzien k, Kowalska A, Brzezinska B, Sokalski L, Jaroch J (2007) Early predictors of adverse left ventricular remodelling after myocardial infarction treated by primary angioplasty. Cardiol J 14: 238-245.

12. Eek C, Grenne B, Brunvand H, Aakhus S, Endresen K, et al. (2010) Strain echocardiography and wall motion score index predicts final infarct size in patients with non-ST-segment-elevation myocardial infarction. Circ Cardiovasc Imaging 3: 187-194.

13. Gaudron P, Eilles C, Kugler I, Ertl G (1993) Progressive left ventricular dysfunction and remodeling after myocardia infarction: potential mechanisms and early predictors. Circulation 87: 755-763.
14. Pipilis A, Meyer TE, Ormerod D, Flather M, Sleight P (1992) Early and late changes in left ventricular filling after acute myocardial infarction and the effect of infarct size. Am J Cardiol 70: 1397-1401.

15. Popovic AD, Neskovic AN, Marinkovic J, Lee JC, Tan M, et al. (1996) Serial assessment of left ventricular chamber stiffness after acute myocardial infarction. Am J Cardiol 77: 361-364.

16. Lacalzada J, de la Rosa A, Izquierdo MM, Jiménez JJ, Iribarren JL, et al. (2015) Left ventricular global longitudinal systolic strain predicts adverse remodeling and subsequent cardiac events in patients with acute myocardial infarction treated with primary percutaneous coronary intervention. Int J Cardiovasc Imaging 31: 575-584.

17. Joyce E, Hoogslag GE, Leong DP, Debonnaire P, Katsanos S, et al. (2014) Association between left ventricular global longitudinal strain and adverse left ventricular dilatation after ST-segment-elevation myocardial infarction. Circ Cardiovasc Imaging 7: 74-81.

18. Bonios MJ, Kaladaridou A, Tasoulis A, Papadopoulou E, Pamboukas C, et al. (2014) Value of apical circumferential strain in the early post-myocardial infarction period for prediction of left ventricular remodeling. Hellenic $\mathrm{J}$ Cardiol 55: 305-312.

19. Aikawa Y, Rohde L, Plehn J, Greaves SC, Menapace F, et al. (2001) Regional wall stress predicts ventricular remodeling after anteroseptal myocardial infarction in the Healing and Early Afterload Reducing Trial (HEART): An echocardiography-based structural analysis. Am Heart J 141: 234242.

20. Huttin $O$, Coiro $S$, Selton-Suty $C$, Juillière $Y$, Donal $E$, et al. (2016) Prediction of left ventricular remodeling after a myocardial infarction: Role of myocardial deformation: A systematic review and meta analysis. PLoS One 11: e0168349.

21. Gjesdal O, Helle-Valle T, Hopp E, Lunde K, Vartdal T, et al. (2008) Noninvasive separation of large, medium, and small myocardial infarcts in survivors of reperfused ST-elevation myocardial infarction: a comprehensive tissue Doppler and speckle-tracking echocardiography study. Circ Cardiovasc Imaging 1: 189-196.

22. Abate E, Hoogslag GE, Leong DP, Bertini M, Antoni ML, et al. (2014) Association between multilayer left ventricular rotational mechanics and the development of left ventricular remodeling after acute myocardial infarction. J Am Soc Echocardiogr 27: 239-248. 